\title{
Characterization of NiO/CoPc nanocomposite material synthesized by solvent evaporation route
}

\author{
P. A. Sheena ${ }^{1,2} \cdot$ K. P. Priyanka ${ }^{3} \cdot$ A. Sreedevi ${ }^{3} \cdot$ Thomas Varghese $^{3}$
}

Received: 22 May 2018 / Accepted: 25 June 2018 / Published online: 29 June 2018

(c) The Author(s) 2018

\section{Abstract}

Nickel oxide/cobalt phthalocyanine ( $\mathrm{NiO}-\mathrm{CoPc})$ nanocomposite is synthesized by solvent evaporation method. The synthesized nanocomposite is characterized for thermal, structural, and optical properties. Thermogravimetric and differential thermal analysis results proved the thermal stability of the sample. XRD patterns revealed an average crystallite size of 16 and $17.5 \mathrm{~nm}$, respectively, for the pure and nanocomposite samples. The formation of $\mathrm{NiO} / \mathrm{CoPc}$ nanocomposite is confirmed by the FTIR results. The characteristic B and Q bands of metal phthalocyanines are visible in the absorption spectrum. A decrease in band gap and an enhanced absorption in the visible region are observed for the nanocomposite. The PL emission spectrum of the nanocomposite exhibits fluorescence quenching which makes them suitable for solar cells and photocatalysis. This work constitutes the first report on the synthesis and characterization of the NiO/CoPc nanocomposite.

\section{Graphical abstract}

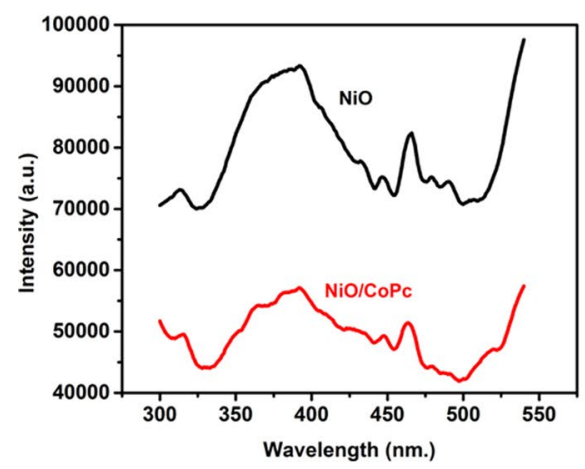

\section{$\mathrm{NiO} / \mathrm{CoPc}$ nanocomposite}
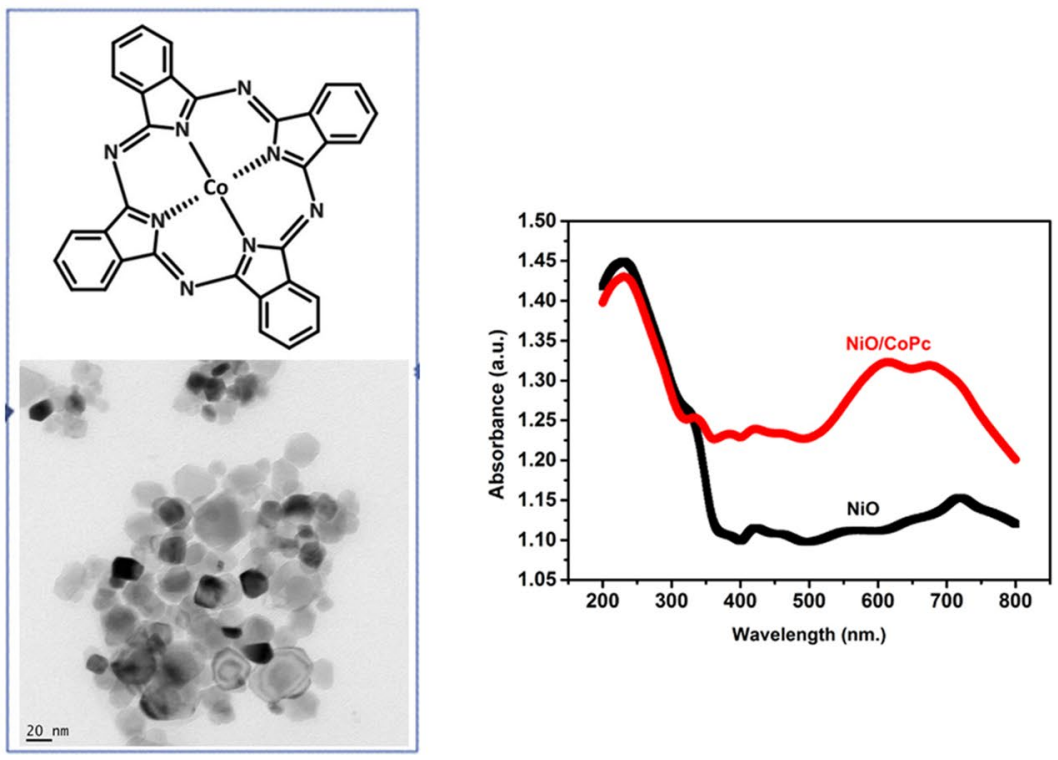

Keywords $\mathrm{NiO} / \mathrm{CoPc}$ nanocomposite $\cdot$ Solvent evaporation $\cdot \mathrm{UV}$-visible absorption $\cdot$ Photoluminescence

Thomas Varghese

nanoncm@gmail.com

Extended author information available on the last page of the article 


\section{Introduction}

Nanocomposites are materials of considerable interest because of their unique design and excellent properties. The combination of organic/inorganic nanocomposites has attracted much attention because of the blending of their distinct physical and chemical properties. There are a rich variety of possible combinations of organic-inorganic materials. Organic materials offer interesting optical properties, structural flexibility, tunable electronic properties and the potential for semiconducting behaviour [1]. Phthalocyanines are p-type organic semiconductors with high stability, having wide range of applications from medicine to microelectronics [2].Out of these; metal phthalocyanines (M.Pc) have invited attention due to their good thermal and chemical stability, photoconductivity and semi-conducting nature. Their thermal and chemical stability are important properties that make them suitable for electrochemical sensors [3]. The properties of M.Pcs are determined by the conjugated $\pi$ electron ring system of the molecule. Due to their high electron transfer abilities, M.Pcs are promising candidates in the field of molecular electronics, opto-electronics, etc. The potential applications of M.Pcs include solar energy conversion [4], photo detectors [5, 6], chemical sensors [7], gas sensors [8] and nonlinear optics [9]. In the other hand, inorganic metal nanoparticles exhibit good thermal and mechanical stability, high carrier mobility, and varied magnetic and dielectric properties [1].

Pure single crystalline NiO is identified as a Mott-Hubbard insulator having very low conductivity at ordinary temperatures. It is reported that the presence of $\mathrm{Ni}^{2+}$ vacancies makes nanosized $\mathrm{NiO}$ a wide band gap p-type semiconductor [10]. The structural and optical properties of $\mathrm{NiO}$ can be finely tuned with the incorporation of $\mathrm{CoPc}$ into the $\mathrm{NiO}$ lattice. In the present work, solvent evaporation method is employed to synthesize $\mathrm{NiO} / \mathrm{CoPc}$ nanocomposite. The thermal, structural and optical properties of the nanocomposite are studied and compared with that of $\mathrm{NiO}$ nanoparticles. This is the first report on the synthesis and characterization of $\mathrm{NiO} / \mathrm{CoPc}$ nanocomposites. However, literatures are available on the study of other metal oxide/CoPc nanocomposites. Priyanka et al. have reported the improved visible light photocatalytic degradation of organic dyes using $\mathrm{TiO}_{2} / \mathrm{CoPc}$ nanocomposite [11]. CoPc-loaded nanotitania is used for the photocatalytic reduction of carbon dioxide as reported by Liu et al. [12]. Babitha et al. have observed a reduction in band gap for $\mathrm{CeO}_{2} / \mathrm{CoPc}$ nanocomposite synthesized by solvent evaporation method [13].

\section{Experimental details}

\section{Materials}

All the chemicals used for the synthesis are of analytical grade. Nickel nitrate hexahydrate $\left[\mathrm{Ni}\left(\mathrm{NO}_{3}\right)_{2} \cdot 6 \mathrm{H}_{2} \mathrm{O}\right.$, $99.8 \%$, Merck], ammonium carbonate $\left[\left(\mathrm{NH}_{4}\right)_{2} \mathrm{CO}_{3}, 99.9 \%\right.$, Merck], cobalt phthalocyanine (CoPc, Sigma Aldrich), dimethyl formamide, dimethyl sulphoxide and ethanol (Merck) are used for the synthesis of the nanocomposite. Distilled water is used for the synthesis.

\section{Synthesis of NiO-CoPc nanocomposite}

The NiO-CoPc nanocomposite is prepared by solvent evaporation method. A solvent mixture containing 50\% dimethyl sulphoxide, $30 \%$ dimethyl formamide and $20 \%$ ethanol is prepared. $1 \mathrm{wt} \%$ cobalt phthalocyanine is dissolved in the mixture under constant magnetic stirring and simultaneous heating at $50{ }^{\circ} \mathrm{C}$. $\mathrm{NiO}$ nanoparticles prepared by chemical precipitation method and calcined at $500{ }^{\circ} \mathrm{C}$ are gradually added to this solution. The procedure adopted for the synthesis of $\mathrm{NiO}$ nanoparticles is reported elsewhere [14]. After complete evaporation of the solvent mixture, the obtained material is washed several times to remove remaining organic solvents and dried at $100{ }^{\circ} \mathrm{C}$ in a hot air oven for $18 \mathrm{~h}$. The scheme for the synthesis is shown in Fig. 1.

\section{Characterization}

The thermal behaviour of the $\mathrm{NiO} / \mathrm{CoPc}$ nanocomposite from room temperature to $880{ }^{\circ} \mathrm{C}$ is studied by thermo gravimetric analysis (TGA) and differential thermal analysis (DTA) using Perkin Elmer STA 6000, at a heating rate of $20{ }^{\circ} \mathrm{C} \mathrm{min}{ }^{-1}$. The structural characterization is done by PXRD method using Bruker D8 Advance X-ray diffractometer $\left(\lambda=1.5406 \AA\right.$, step size $=0.020^{\circ}$ and step time $=32.8 \mathrm{~s})$ with $\mathrm{CuK} \alpha$ radiation $(\lambda=1.5406 \AA$, $\mathrm{X}$-ray tube voltage $=40 \mathrm{kV}$ and current $=35 \mathrm{~mA}$ ) from 0 to $90{ }^{\circ} \mathrm{C}$. TEM and HRTEM images are recorded at an accelerating voltage of $200 \mathrm{kV}$ on a Jeol/JEM 2100 instrument. Thermo Nicolet, Avatar 370 instrument is used to record Fourier transform infrared spectra of the samples in the range 4000-400 $\mathrm{cm}^{-1}$. The optical absorption spectra of the samples are recorded using Shimadzu 2600/2700 UV-visible spectrophotometer in the wavelength range of 200-800 $\mathrm{nm}$. PL spectra of the samples at room temperature are measured using a Fluoromax 3 spectrophotometer. 
Fig. 1 Scheme of synthesis of $\mathrm{NiO} / \mathrm{CoPc}$ nanocomposite

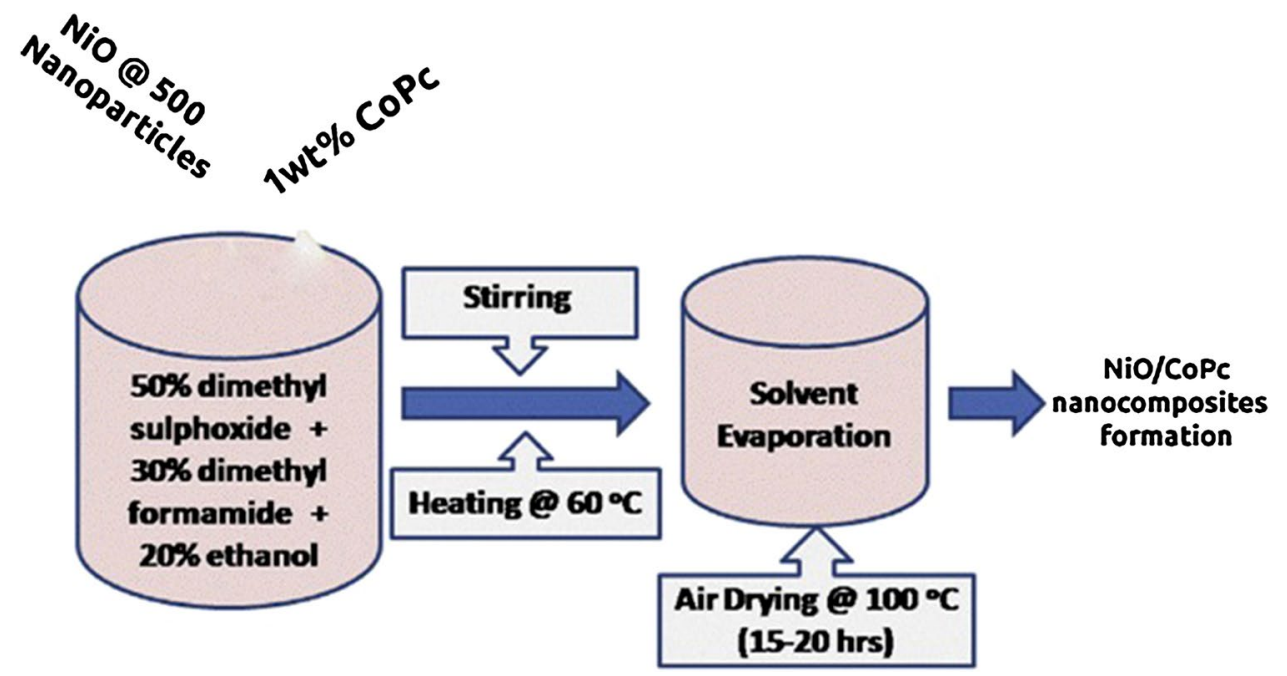

\section{Results and discussion}

\section{Thermogravimetric analysis}

TG/DTG curves of the prepared precursor and $\mathrm{NiO} / \mathrm{CoPc}$ nanocomposite are displayed in Fig. 2. The precursor decomposed completely at around $350{ }^{\circ} \mathrm{C}$ to form nickel oxide. A small weight loss of about $6 \%$ is observed in the TG curve of the composite which confirms its thermal stability. The weight loss up to $400{ }^{\circ} \mathrm{C}$ is related to the evaporation of trapped solvents such as water and ethanol. It is reported that CoPc is stable up to about $400{ }^{\circ} \mathrm{C}$ and decomposition starts around $425^{\circ} \mathrm{C}$ [15]. This may be the reason for a comparatively sharp weight loss $(1 \%)$ around $400{ }^{\circ} \mathrm{C}$, which occurs by the partial decomposition of macrocyclic structure which results in the loss of low weight atoms from the composite structure [16].

The DTG curve of the sample shows an endothermic peak around $60{ }^{\circ} \mathrm{C}$. This represents a weight loss due to the combustion of organic residues. A sharp endothermic peak positioned around $428^{\circ} \mathrm{C}$ also indicates a change of weight suggesting the oxidative degradation of the sample. Thermal analysis confirms the thermal stability of the nanocomposite in the temperature range.

\section{XRD analysis}

The structure, composition and purity of the prepared samples are analysed using XRD. Figure 3 shows the X-ray diffraction patterns of $\mathrm{NiO}$ and $\mathrm{NiO} / \mathrm{CoPc}$ samples. The sharpness of diffraction peaks indicates the crystallinity of the sample. The observed peak positions at $2 \theta$ values $37.424,43.463,63.03075 .554$, and $79.53{ }^{\circ} \mathrm{C}$ are indexed as (111), (200), (220), (311), and (222) crystal planes of $\mathrm{NiO}$, respectively (space group: $\mathrm{Fm} 3 \mathrm{~m}$ ), with lattice constant $a=4.161 \AA$ (JCPDS card No. 73-1519). Due to the low concentration of $\mathrm{CoPc}$, no peaks of phthalocyanine are observed in the diffraction pattern. However, all the
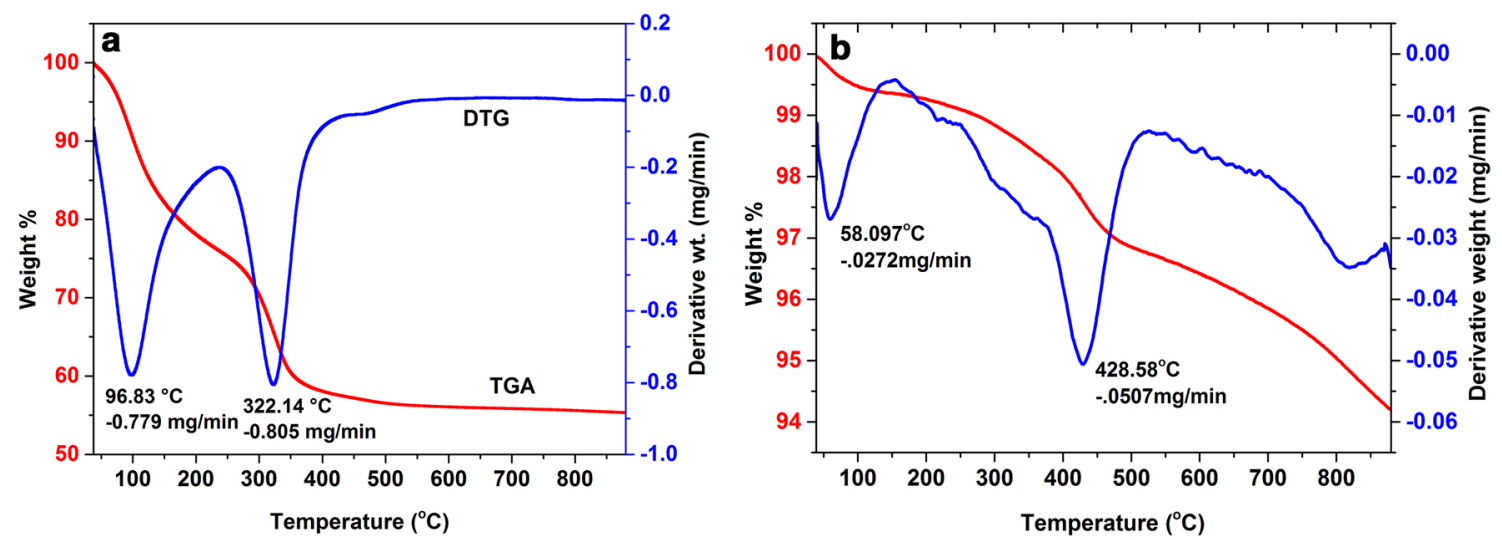

Fig. 2 TGA/DTG curves of $\mathbf{a} \mathrm{NiO}$ and $\mathbf{b} \mathrm{NiO} / \mathrm{CoPc}$ nanocomposite 


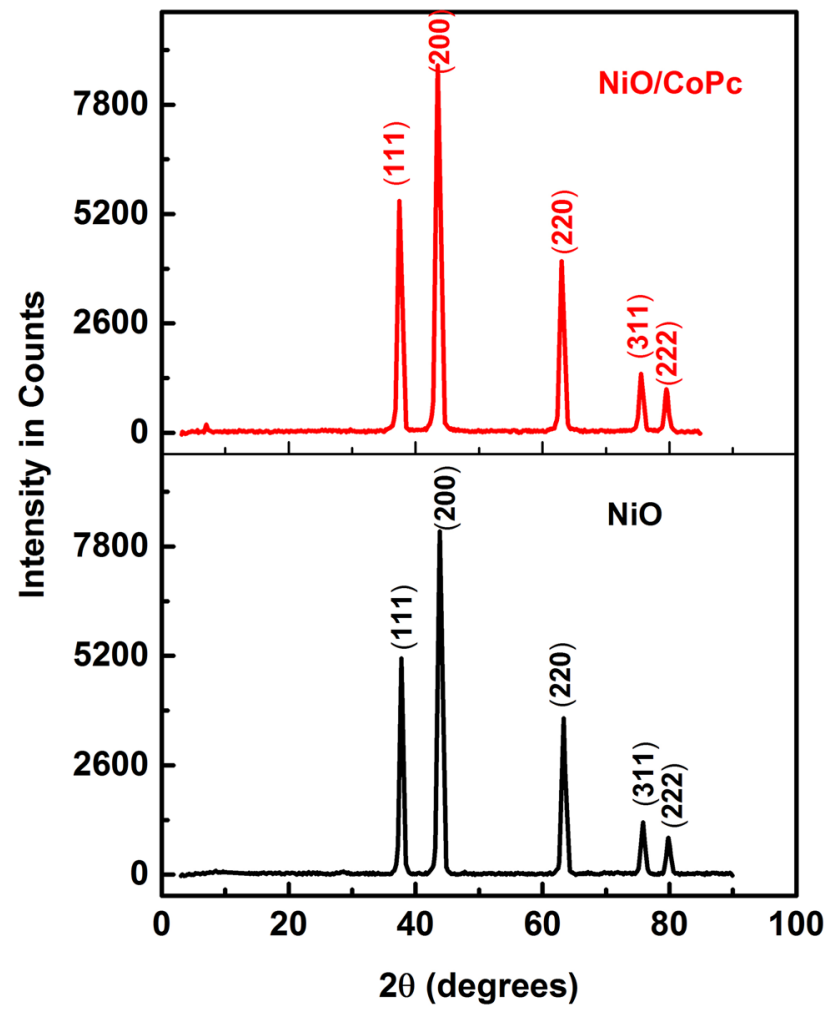

Fig. 3 XRD spectra of $\mathrm{NiO}$ and $\mathrm{NiO} / \mathrm{CoPc}$ nanocomposite

Table 1 Geometric parameters of $\mathrm{NiO}$ and $\mathrm{NiO} / \mathrm{CoPc}$ from XRD spectra

\begin{tabular}{llll}
\hline Sample & \multicolumn{2}{l}{ Crystallite size $(\mathrm{nm})$} & Micro-strain \\
\cline { 2 - 4 } & $\begin{array}{l}\text { Scherrer equa- } \\
\text { tion }\end{array}$ & $W-H$ analysis & \\
\hline $\mathrm{NiO}$ & 16 & 18.5 & $6.656 \times 10^{-4}$ \\
$\mathrm{NiO} / \mathrm{CoPc}$ & 17.5 & 21.1 & $7.259 \times 10^{-4}$ \\
\hline
\end{tabular}

prominent peaks are shifted slightly to lower angle side for the nanocomposite.

The structural parameters of $\mathrm{NiO} / \mathrm{CoPc}$ nanocomposite are compared with that of pure $\mathrm{NiO}$ in Table 1.The average crystallite size of $\mathrm{NiO}$ and $\mathrm{NiO} / \mathrm{CoPc}$ samples obtained using Scherrer equation, $D=k \lambda / \beta \cos \theta$ [17] are 16 and $17.5 \mathrm{~nm}$, respectively. The increase in crystallite size and interplanar spacing for the composite shows the growth of unit cell with the inclusion of phthalocyanine.

The size and micro-strain contributions to the broadening of XRD peaks is calculated by Williamson-Hall equation, $\beta \cos \theta=k \lambda / D+4 \varepsilon \sin \theta$ [18]. The micro-strain values for $\mathrm{NiO}$ and $\mathrm{NiO} / \mathrm{CoPc}$ are $6.656 \times 10^{-4}$ and $7.259 \times 10^{-4}$, respectively. The presence of oxygen vacancies, dislocations and crystal imperfections may contribute to the micro-strain. The defect centres formed due to the insertion of $\mathrm{CoPc}$ into the $\mathrm{NiO}$ lattice are responsible for the increase in micro-strain.

\section{TEM analysis}

To reveal the morphology and size of the synthesized particles, TEM images of pure $\mathrm{NiO}$ and the nanocomposite are recorded as displayed in Fig. 4. The particle size of the composite material ranges from 20 to $25 \mathrm{~nm}$. The bright field image of the composite shows the cube-like shape of the particles which are well-dispersed with smooth surfaces. The crystallinity of the sample is confirmed by the bright spots in the SAED pattern. The particle size distribution of $\mathrm{NiO} /$ $\mathrm{CoPc}$ nanocomposite is plotted in the histogram in Fig. 5.

\section{FTIR analysis}

FTIR spectra of pure and nanocomposite samples are presented in Fig. 6a. The spectrum of the nanocomposite shows some prominent peaks which confirm the presence of CoPc. Table 2 presents the observed modes in $\mathrm{NiO}$ and $\mathrm{NiO} / \mathrm{CoPc}$, along with the reported values for CoPc.

The intense peak observed in both samples at $412 \mathrm{~cm}^{-1}$ is due to Ni-O stretching vibration. The broad band centred at $3430 \mathrm{~cm}^{-1}$ is assigned to $\mathrm{O}-\mathrm{H}$ stretching vibrations and the band at $1625 \mathrm{~cm}^{-1}$ is attributed to $\mathrm{H}-\mathrm{O}-\mathrm{H}$ bending vibration mode $[19,20]$. Figure $6 \mathrm{~b}$ shows FTIR spectrum of the nanocomposite in the range $1500-700 \mathrm{~cm}^{-1}$. The bands at 723 (C-H out of plane deformation), 918 (metal ligand vibration), $1112(\mathrm{C}-\mathrm{H}$ in plane bending), $1156(\mathrm{C}-\mathrm{N}$ in plane bending), 1287 (C-N stretching) and $1330 \mathrm{~cm}^{-1}(\mathrm{C}-\mathrm{C}$ stretching) confirm the existence of $\mathrm{CoPc}$ in the composite [21]. The band located at $723 \mathrm{~cm}^{-1}$ in $\mathrm{NiO} / \mathrm{CoPc}$ represents the characteristic $\alpha$-phase of CoPc [13].

\section{UV-visible studies}

Figure 7 shows the UV-visible absorption spectra of $\mathrm{NiO}$ and $\mathrm{NiO} / \mathrm{CoPc}$ composite in the range $200-800 \mathrm{~nm}$.

A strong absorption in the range $200-300 \mathrm{~nm}$ centred at $235 \mathrm{~nm}$ is observed in both samples, which are attributed to band gap absorption in $\mathrm{NiO}$ [22]. The absorption peak of $\mathrm{NiO}$ arises from the transition between $2 \mathrm{p}$ states of oxygen in the top of the valence band and $3 \mathrm{~d}$ states of $\mathrm{Ni}$ at the bottom of the conduction band [23].

Compared to $\mathrm{NiO}, \mathrm{NiO} / \mathrm{CoPc}$ shows very good absorption in the range $300-750 \mathrm{~nm}$. This corresponds to the $\mathrm{B}$ band (Sorret band) and Q band which are characteristic of metal phthalocyanines. This indicates the successful incorporation of $\mathrm{CoPc}$ in $\mathrm{NiO}$. Both these bands arise from $\pi-\pi^{*}$ transitions of the conjugated macrocycle of $18 \pi$-electrons $[24,25]$. The two absorption peaks in the $\mathrm{Q}$ band are at 2.02 and $1.83 \mathrm{eV}$. The higher-energy peak (Q1) has a slightly 

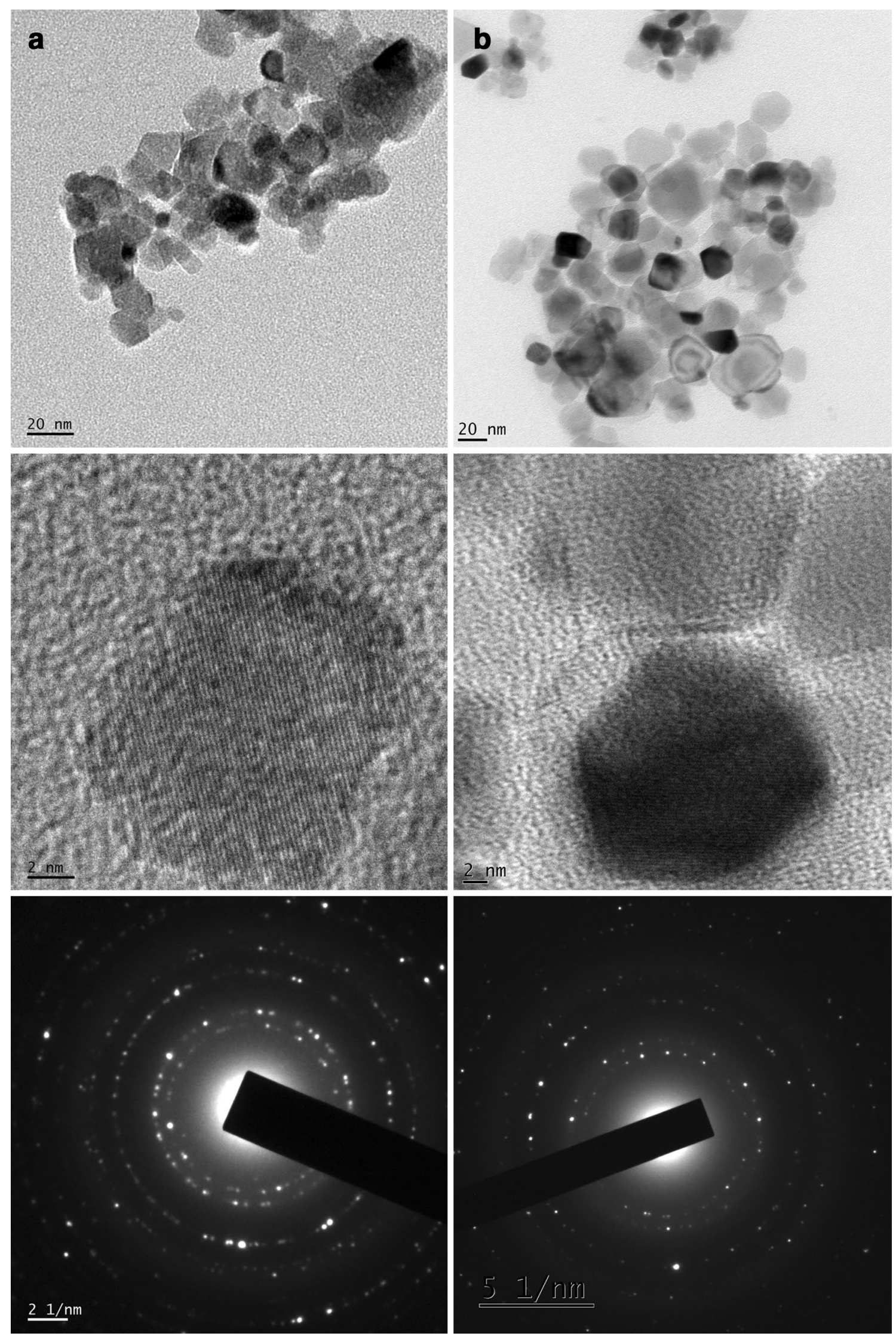

Fig. 4 TEM images of $\mathrm{NiO}$ and $\mathrm{NiO} / \mathrm{CoPc}$ nanocomposite 


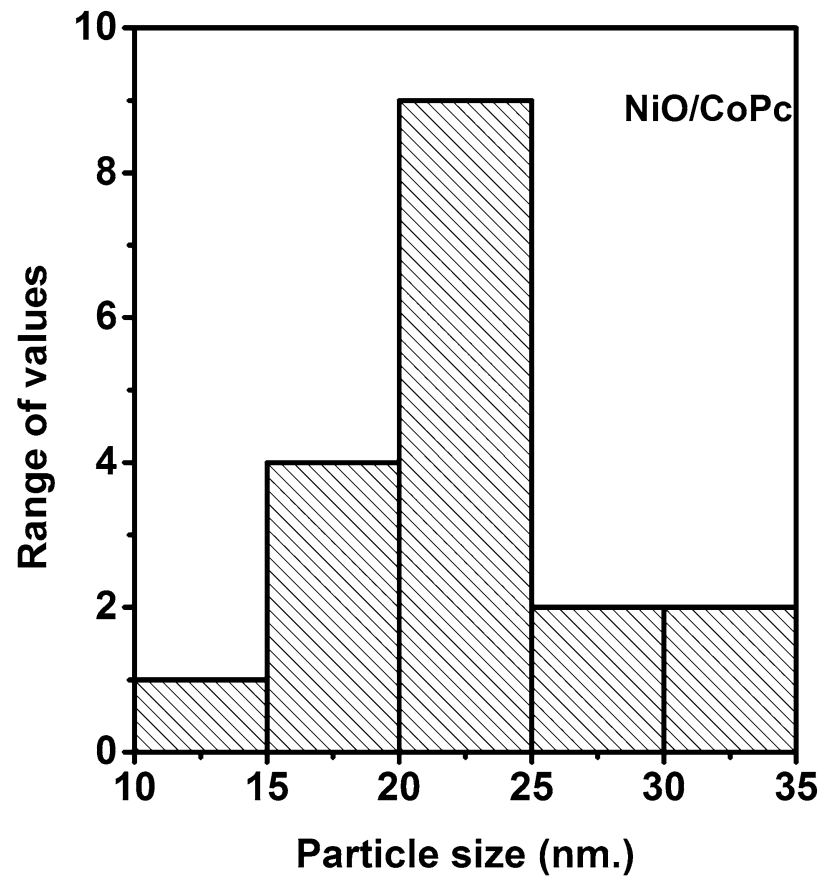

Fig. 5 Size distribution of $\mathrm{NiO} / \mathrm{CoPc}$ nanocomposite

larger intensity compared to the second peak (Q2), which is a typical feature of $\operatorname{CoPc} \alpha$-phase [26]. The electrons in the $\pi$ orbital which overlap between molecules are responsible for the absorption spectra [27].

The plot of $h \nu$ vs. $(\alpha h \nu)^{2}$ for the pure sample and the nanocomposite are displayed in Fig. 8. The intrinsic band gap energies obtained are 3.24 and $3.09 \mathrm{eV}$ for $\mathrm{NiO}$ and $\mathrm{NiO} / \mathrm{CoPc}$, respectively. The decrease in band gap for the composite is due to crystallite growth which results in the broadening of highest occupied molecular orbit in the valence band (HOMO) and the lowest unoccupied molecular orbit in the conduction band (LUMO) energy levels. The

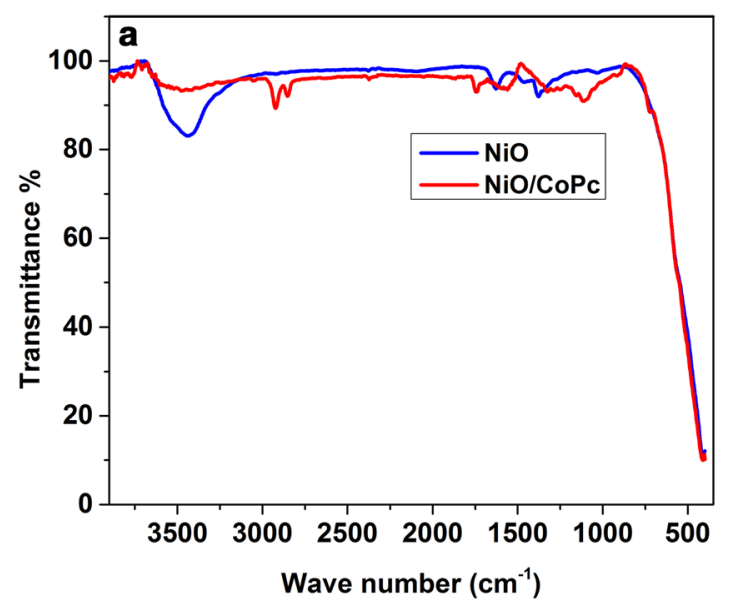

Table 2 Comparison of Infrared active modes of $\mathrm{NiO}$ and $\mathrm{NiO} / \mathrm{CoPc}$ nanocomposite

\begin{tabular}{|c|c|c|c|}
\hline \multicolumn{2}{|c|}{ Samples } & \multirow{2}{*}{$\begin{array}{l}\text { Literature values } \\
\text { CoPc [21] }\end{array}$} & \multirow[t]{2}{*}{ Band assignments } \\
\hline $\mathrm{NiO}$ & $\mathrm{NiO} / \mathrm{CoPc}$ & & \\
\hline \multirow[t]{7}{*}{410} & 414 & - & $\mathrm{Ni}-\mathrm{O}$ stretching vibration \\
\hline & 723 & 721 & $\begin{array}{l}\mathrm{C}-\mathrm{H} \text { out of plane deforma- } \\
\text { tion ( } \alpha \text { phase })\end{array}$ \\
\hline & 918 & 911 & Metal ligand vibration \\
\hline & 1112 & 1117 & $\mathrm{C}-\mathrm{H}$ in plane bending \\
\hline & 1156 & 1162 & $\mathrm{C}-\mathrm{N}$ in plane bending \\
\hline & 1287 & 1287 & $\mathrm{C}-\mathrm{N}$ stretching in isoindole \\
\hline & 1330 & 1329 & $\mathrm{C}-\mathrm{C}$ stretching in isoindole \\
\hline
\end{tabular}

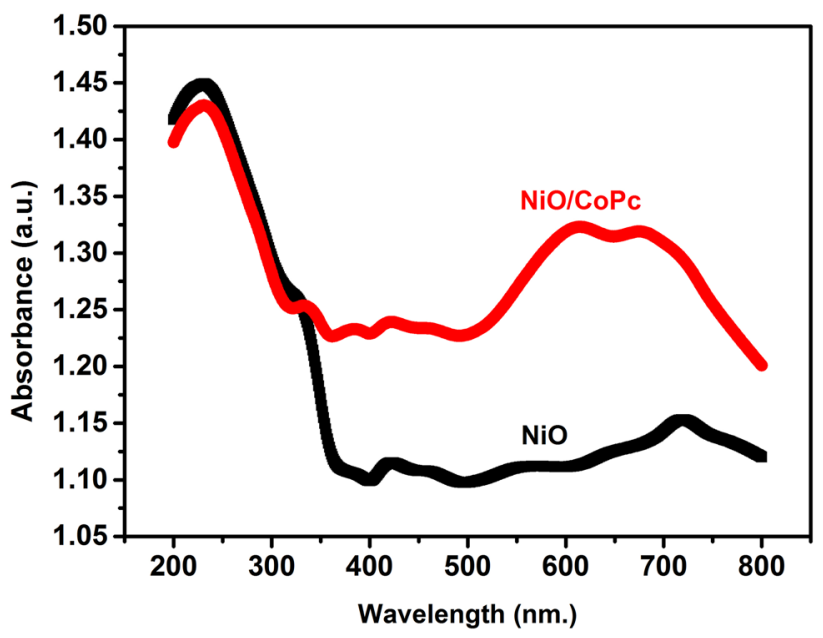

Fig. 7 Absorption spectra of $\mathrm{NiO}$ and $\mathrm{NiO} / \mathrm{CoPc}$ nanocomposite

addition of $\mathrm{CoPc}$ into $\mathrm{NiO}$ has extended the absorption from $\mathrm{UV}$ to visible region of $\mathrm{NiO}$, suggesting visible light photocatalytic application of the nanocomposite.

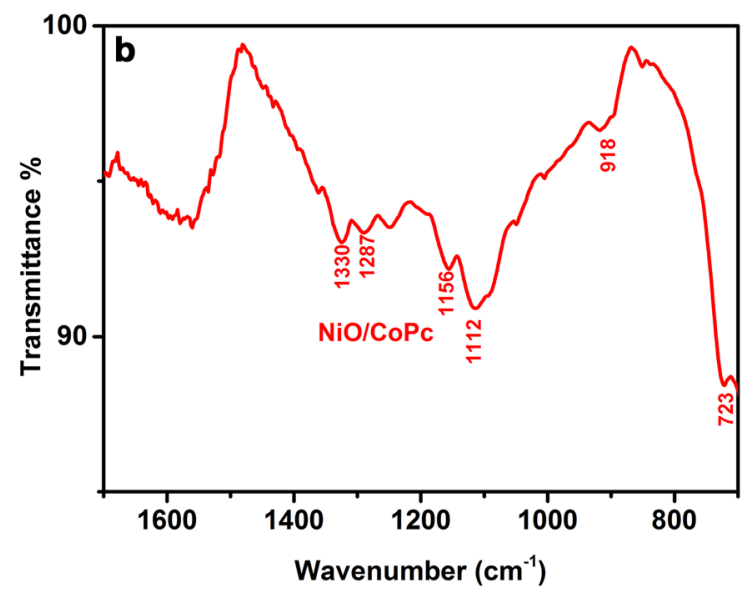

Fig. 6 FTIR spectra of $\mathbf{a} \mathrm{NiO}$ and $\mathbf{b} \mathrm{NiO} / \mathrm{CoPc}$ nanocomposite 


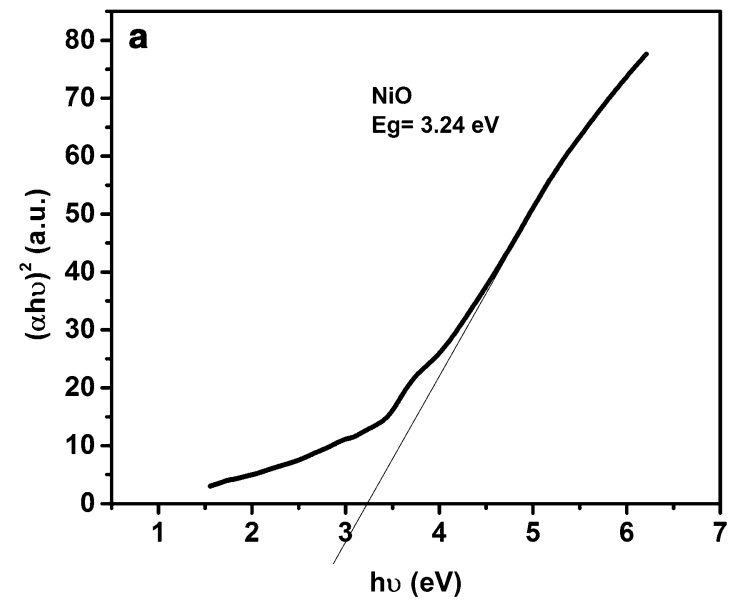

Fig. $8 h \nu$ vs. $(\alpha h \nu)^{2}$ plot of $\mathbf{a} \mathrm{NiO}$ and $\mathbf{b ~ N i O / C o P c}$ nanocomposite

\section{PL studies}

Room temperature photo luminescence spectra $\left(\lambda_{\text {ex }}=280 \mathrm{~nm}\right)$ for $\mathrm{NiO}$ and $\mathrm{NiO} / \mathrm{CoPc}$ are shown in Fig. 9. There is a broad emission band ranging from 325 to $425 \mathrm{~nm}$ with a peak located at $395 \mathrm{~nm}$. This corresponds to the emission of free and bound excitons produced by oxygen vacancies and surface defects of $\mathrm{NiO}$. Several shoulder peaks at $314,447,463,479$ and $489 \mathrm{~nm}$ in the violet-blue region are also observed for both the samples. The shape of the PL spectra of the composite is similar to that of $\mathrm{NiO}$ indicating that the inclusion of CoPc does not cause new fluorescent phenomena because of strong spin-orbit interaction [28]. As the surface oxygen vacancies of $\mathrm{NiO}$ can bind electrons to form excitons, the fluorescent effects of the composites are caused by the surface structure of $\mathrm{NiO}$.

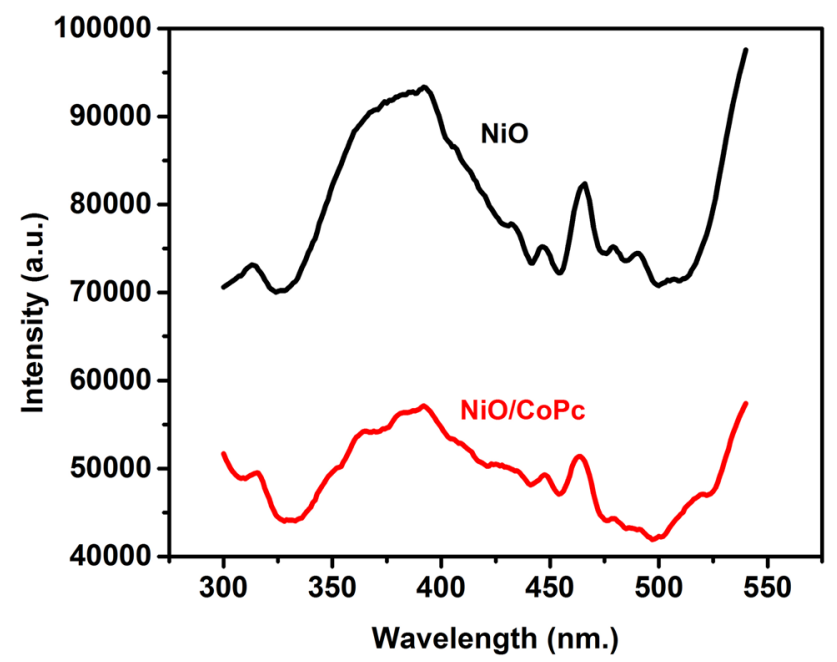

Fig. 9 PL spectra of $\mathrm{NiO}$ and $\mathrm{NiO} / \mathrm{CoPc}$ nanocomposites

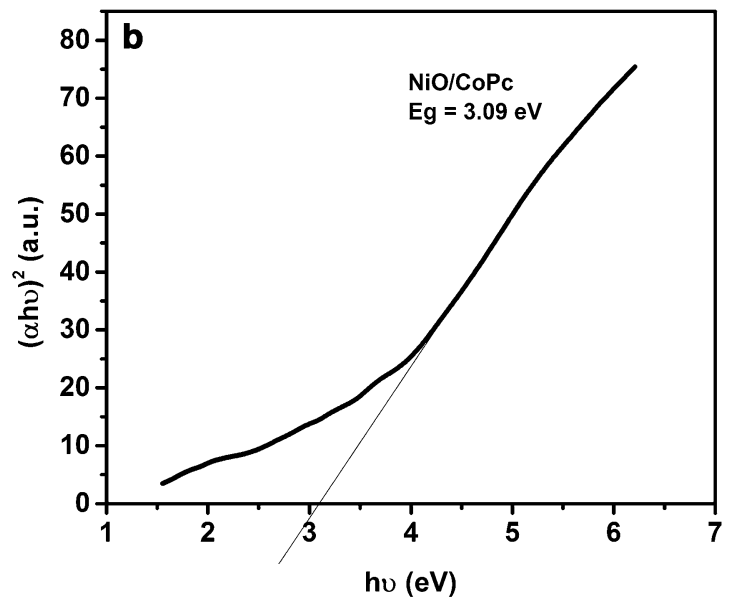

The efficiency of electron trapping and recombination of electrons and holes determines the emission peak intensity. Compared to pure NiO, PL spectrum of the composite suffers a reduction in intensity. This emission quenching represents the interaction and electron transfer process between $\mathrm{CoPc}$ and $\mathrm{NiO}$. The result indicates that the composite can effectively block the electron-hole recombination in $\mathrm{NiO}$, and improve the efficiency of separation of electrons and holes [29]. This will in turn enhance the photocatalytic activity of the composite. Hence, the photo-efficiency and photo-activity of $\mathrm{NiO}$ nanoparticles can be improved with the addition of CoPc of appropriate concentration which makes them suitable for potential applications in solar cells and photocatalysis.

\section{Conclusion}

$\mathrm{NiO} / \mathrm{CoPc}$ nanocomposite is synthesized by simple solvent evaporation method. TGA/DTG studies confirm the thermal stability of the sample. The formation of $\mathrm{NiO} / \mathrm{CoPc}$ nanocomposite is confirmed by the XRD, TEM and FTIR results. UV-visible absorption studies indicate a decrease in band gap energy along with an enhanced and extended visible light absorption for the nanocomposite. The emission quenching in PL spectrum makes them suitable for solar cells and photocatalysis and for potential applications in varied fields.

Acknowledgements The authors acknowledge Nirmala College, Muvattupuzha and Newman College, Thodupuzha for providing the facilities to conduct this study. They are also grateful to SAIF Cochin and Maharajas College, Ernakulam for the technical support rendered. The first author acknowledges the University Grants Commission for facilitating the research work through FDP. 
Open Access This article is distributed under the terms of the Creative Commons Attribution 4.0 International License (http://creativeco mmons.org/licenses/by/4.0/), which permits unrestricted use, distribution, and reproduction in any medium, provided you give appropriate credit to the original author(s) and the source, provide a link to the Creative Commons license, and indicate if changes were made.

\section{References}

1. Anees, A.A., Khan, M.A.M., Naziruddin, K.M., Salman, A.A., Alhoshan, M., Alsalhi, M.S.: Optical and electrical properties of electrochemically deposited polyaniline/ $\mathrm{CeO}_{2}$ hybrid nanocomposite film. J. Semicond. 32, 043001-043006 (2011)

2. Leznoff, C.C., Lever, A.B.P.: Phthalocyanines: properties and applications. Wiley, New York (1989)

3. Saravanan, S., Joseph Mathai, C., Anantharaman, M.R., Venkatachalam, S., Prabhakaran, P.V.: Dielectric and conductivity studies on cobalt phthalocyanine tetramers. J. Appl. Polym. Sci. 9, 2529-2535 (2004)

4. Yuen, A.P., Jovanovic, S.M., Hor, A., Klenkler, R.A., Devenyi, G.A., Loutfy, R.O., Preston, J.S.: Photovoltaic properties of $M$-phthalocyanine/fullerene organic solar cells. Sol. Energy 86, 1683-1688 (2012)

5. Zhang, X., Lin, Y., Guo, W., Zhu, J.: Spectroscopic insights on imidazole substituted phthalocyanine photosensitizers: fluorescence properties, triplet state and singlet oxygen generation. Spectrochim. Acta Part A Mol. Biomol. Spectrosc. 133, 752-758 (2014)

6. Wang, Y., Dejian Liang, D.: Solvent-stabilized photoconductive metal phthalocyanine nanoparticles: preparation and application in single-layered photoreceptors nanoparticles: preparation and application in single-layered photoreceptors. Adv. Mater. 22, 1521-1525 (2010)

7. Öztürk, Z.Z., Kılınç, N., Atilla, D., Gürek, A.G., Ahsen, V.: Recent studies chemical sensors based on phthalocyanines. J. Porphyr. Phthalocyanines 13, 1179-1187 (2009)

8. Xie, D., Jiang, Y., Pan, W., Jiang, J., Wu, Z., Li, Y.: The characteristics and gas-sensing property of bis[phthalocyaninato] rare earth complexes based charge-flow transistor. Sens. Actuators B 81, 210-217 (2002)

9. Mathews, S.J., Chaitanya Kumar, S., Giribabu, L., Venugopal Rao, S.: Nonlinear optical and optical limiting properties of phthalocyanines in solution and thin films of PMMA at $633 \mathrm{~nm}$ studied using a cw laser. Mater. Lett. 61, 4426-4431 (2007)

10. Madhu, G., Bose, V.C., Aiswaryaraj, A.S., Maniammal, K., Biju, V.: Defect dependent antioxidant activity of nanostructured nickel oxide synthesized through a novel chemical method. Colloids Surf. A Physicochem. Eng. Asp. 429, 44-50 (2013)

11. Priyanka, K.P., Sankararaman, S., Balakrishna, K.M., Varghese, T.: Enhanced visible light photocatalysis using $\mathrm{TiO}_{2} /$ phthalocyanine nanocomposites for the degradation of selected industrial dyes. J. Alloys Compd. 720, 541-549 (2017)

12. Liu, S., Zhao, Z., Wang, Z.: Photocatalytic reduction of carbon dioxide using sol-gel derived titania-supported CoPc catalysts. Photochem. Photobiol. Sci. 6, 695-700 (2007)

13. Babitha, K.K., Priyanka, K.P., Sreedevi, A., Jaseentha, O.P., Varghese, T.: Structural modifications and extended spectral response of $\mathrm{CeO}_{2} / \mathrm{CoPc}$ nanocomposites for potential applications. Int. J. Appl. Ceram. Technol. 13, 670-677 (2016)
14. Sheena, P.A., Priyanka, K.P., Aloysius Sabu, N., Sabu, B., Varghese, T.: Effect of calcination temperature on the structural and optical properties of nickel oxide nanoparticles. Nanosyst. Phys. Chem. Math. 5, 441-449 (2014)

15. Borker, P., Salker, A.V.: Synthesis, characterization and photocatalytic studies of some metal phthalocyanines. Indian J. Chem. Technol. 13, 341-346 (2006)

16. Burgos, F.V., Utsumi, S., Hattori, Y., et al.: Pyrolyzed phthalocyanines as surrogate carbon catalysts: initial insights into oxygentransfer mechanisms. Fuel 99, 106-117 (2012)

17. Cullity, B.D.: Elements of X-Ray Diffraction. Addison-Wesley, Reading (1967)

18. Williamson, G.K., Hall, W.H.: X-ray line broadening from filed aluminum and wolfram. Acta Metall. 1, 22-31 (1953)

19. Anandan, K., Rajendran, V.: Morphological and size effects of $\mathrm{NiO}$ nanoparticles via solvothermal process and their optical properties. Mater. Sci. Semicond. Process. 14, 43-47 (2011)

20. Sheena, P.A., Priyanka, K.P., Sabu, N.A., Gannesh, S., Varghese, T.: Effect of electron beam irradiation on the structure and optical properties of nickel oxide nanocubes. Bull. Mater. Sci. 38, 825-830 (2015)

21. Verma, D., Dash, R., Katti, K.S., Schulz, D.L., Caruso, A.N.: Role of coordinated metal ions on the orientation of phthalocyanine based coatings. Spectrochim. Acta Part A 70, 1180-1186 (2008)

22. Li, X., Zhang, X., Li, Z., Qian, Y.: Synthesis and characteristics of $\mathrm{NiO}$ nanoparticles by thermal decomposition of nickel dimethylglyoximate rods. Solid State Commun. 137, 581-584 (2006)

23. Manna, S., Deb, A.K., Jagannanth, J., De, S.K.: Synthesis and room temperature ferromagnetism in $\mathrm{Fe}$ doped $\mathrm{NiO}$ nanorods. J. Phys. Chem. C 112, 10659-10662 (2008)

24. Rajesh, K.R., Menon, C.S.: Electrical and optical properties of vacuum deposited $\mathrm{ZnPc}$ and $\mathrm{CoPc}$ thin films and application of variable range hopping model. Indian J. Pure Appl. Phys. 43, 964-971 (2005)

25. Seoudi, R., El-Bahy, G.S., El Sayed, Z.A.: Ultraviolet and visible spectroscopic studies of the phthalocyanine and its complexes thin films. Opt. Mater. 29, 304-312 (2006)

26. Sreedevi, A., Priyanka, K.P., Babitha, K.K., Jaseentha, O.P., Varghese, T.: Structural and optical modifications of the $\mathrm{Ag}_{2} \mathrm{WO}_{4} /$ CoPc nanocomposite for potential applications. Eur. Phys. J. Plus 131, 1-7 (2016)

27. Joseph, B., Menon, C.S.: Studies on the optical properties and surface morphology of cobalt Phthalocyanine thin films. J. Chem. 5, 86-92 (2008)

28. Bała, W., Wojdyła, M., Rębarz, M., Szybowic, M., Drozdowski, M., Grodzicki, A., Piszczek, P.: Influence of central metal atom in MPc $(\mathrm{M}=\mathrm{Cu}, \mathrm{Zn}, \mathrm{Mg}, \mathrm{Co})$ on Raman, FT-IR, absorbance, reflectance, and photoluminescence spectra. J. Optoelectron. Adv. Mater. 11, 264-269 (2009)

29. Gu, L., Wang, J., Cheng, H., Zhao, Y., Liu, L., Han, X.: One-step preparation of graphene-supported anatase $\mathrm{TiO}_{2}$ with exposed 001 facets and mechanism of enhanced photocatalytic properties. ACS Appl. Mater. Interfaces. 5, 3085-3093 (2013)

Publisher's Note Springer Nature remains neutral with regard to jurisdictional claims in published maps and institutional affiliations. 


\section{Affiliations}

\section{P. A. Sheena ${ }^{1,2} \cdot$ K. P. Priyanka ${ }^{3} \cdot$ A. Sreedevi ${ }^{3} \cdot$ Thomas Varghese $^{3}$}

1 Department of Physics, M.E.S. Asmabi College, Kodungallur, Padinjare Vemballur, Kerala 680 671, India

2 Department of Physics, Newman College, Thodupuzha, Kerala 685584, India
3 Department of Physics, Nanoscience Research Centre (NSRC), Nirmala College, Muvattupuzha, Kerala 686661, India 